\section{Genotyping pattern of the vacuolating cytotoxin $A$ and cytotoxin associated gene A of the Helicobacter pylori strains detected in fecal samples of household dogs}

\author{
Asieh Bolandi, ${ }^{1}$ Saam Torkan, ${ }^{2}$ \\ Iman Alavi ${ }^{3}$ \\ ${ }^{1}$ Faculty of Veterinary Medicine, \\ University of Tehran; ${ }^{2}$ Department of \\ Small Animal Internal Medicine, \\ Faculty of Veterinary Medicine, \\ Shahrekord Branch, Islamic Azad \\ University, Shahrekord; ${ }^{3}$ Department of \\ Microbiology, Faculty of Basic Sciences, \\ Shahrekord Branch, Islamic Azad \\ University, Shahrekord, Iran
}

\begin{abstract}
In despite of the high clinical impact of Helicobacter pylori, its exact sources and routes of transmission are unknown. Dogs may play an imperative role in the transmission of $H$. pylori to humans. The current investigation was done to study the status of vacA and cagA genotypes in the $H$. pylori strains of dogs. One-hundred and fifty fecal samples were collected from healthy and complicated household dogs. Genomic DNA was extracted from fecal samples and presence of $16 S$ rRNA gene was studied using the PCR amplification. Distribution of $v a c A$ and $\operatorname{cag} A$ genotypes were studied by the multiplex PCR. Thirteen out of 150 fecal samples $(8.66 \%)$ were positive for $H$. pylori $16 S$ rRNA gene. Prevalence of $H$. pylori in healthy and complicated dogs were $5.55 \%$ and $8.57 \%$, respectively. Male had the higher prevalence of $H$. pylori $(\mathrm{P}=0.038)$. The most commonly detected genotypes among the $H$. pylori strains were vacAs1A (61.53\%), cagA (38.46\%), vacAmla (38.46\%), vacAs2 (30.76\%) and vacAm $2(30.76 \%)$. The most commonly detected combined genotypes were slaCagA (30.76\%), slamla (23.07\%), s $2 m 1 a(23.07 \%)$ and $s 2 \operatorname{CagA}(23.07 \%)$. Iranian household dogs harbor $H$. pylori in their fecal samples similar in genotypes of the vacA and $\operatorname{cag} A$ alleles which suggest that complicated and even healthy dogs may be the latent host of the H. pylori and its genotypes. However, supplementary studies are required to found the exact role of dogs as a definitive host of the H. pylori.
\end{abstract}

\section{Introduction}

Dogs are one of the most useful and popular companion animal. Dogs chiefly can affluence loneliness, decrease allergies, depression, anxiety, stress, and variety of human immunological diseases and indorse social interaction, encourage exercise and playfulness, and deliver unqualified love. Dogs are also skilled guard, decent hunters, real narcotic detector and sharp probes. Company of dogs with children can increase their immune levels against many kinds of zoonotic diseases. ${ }^{1}$

Helicobacter pylori (H. pylori) is a gram negative, spiral shaped bacterium of the human stomach. It is considered as one of the most contentious bacteria in the world. H. pylori is responsible for peptic ulcer, gastritis, lymphoma, duodenal ulcer, and gastric cancer. ${ }^{2,3}$ Recorded findings revealed that dogs may play an imperative impact in transmission of $H$. pylori to human. ${ }^{4-6}$ Gastrointestinal H. pylori infections are routine in dogs. ${ }^{4-7}$ Documented data revealed a high homology in the DNA sequence of $H$. pylori strains isolated from household dogs and also those which cause severe gastroenteritis and other types of gastrointestinal diseases in their owners. ${ }^{8}$ Therefore, close contact with healthy and complicated dogs which harbor H. pylori in their stomach has been determined to be a risk factor for human Helicobacter infection. ${ }^{4-8}$

Study the distribution of putative genotypes is essential to assess the microbiological and epidemiological prospective of $H$. pylori in clinical cases. The most imperative virulence genes accompanied with severe cases of $H$. pylori infections are vacuolating cytotoxin $\mathrm{A}(v a c A)$ and cytotoxin associated gene $\mathrm{A}(\operatorname{cag} A) .{ }^{9,10}$ The vacA belongs to the group of genes with mutable structures. This gene is polymorphic, comprising mutable signal regions (type $s 1$ or $s 2$ ) and mid-regions (type $m 1$ or $m 2$ ). The $s 1$ type is supplementary subtyped into $s 1 a, s 1 b$ and $s 1 c$ and the $m 1$ into $m 1 a$ and $m 1 b$ subtypes. The mosaic combination of $\mathrm{s}$ and $\mathrm{m}$-regions regulates the specific cytotoxin and therefore, the pathogenicity of the H. pylori. ${ }^{9}, 10$ The $\operatorname{cag} A$ gene has been detected in the specimens taken from the severe cases of peptic ulcer and gastritis.9-11 Genotyping using these virulence markers is measured as one of the best methods for assess associations between $H$. pylori isolates from diverse clinical samples.

From clinical, epidemiological, microbiological and hygienic prospective, it is important to assess the distribution of putative genotypes of the $H$. pylori in companion animals like dogs. Considering the
Correspondence: Asieh Bolandi, Faculty of Veterinary Medicine, University of Tehran, Qareeb Street, Azadi Av., P.O. Box 141556453, Tehran, Iran.

Tel.: +98.912.0310919.

E-mail: drhodabolandi@gmail.com

Key words: Helicobacter pylori, Genotypes, VacA, CagA, Household dogs.

Acknowledgements: The authors would like to thanks from all of the Small Animal Clinics of the Tehran province for their clinical supports. This work was supported by the authors.

Contributions: the authors contributed equally.

Conflict of interest: the authors declare no potential conflict of interest.

Received for publication: 29 June 2017.

Accepted for publication: 8 August 2017.

This work is licensed under a Creative Commons Attribution NonCommercial 4.0 License (CC BY-NC 4.0).

(C) Copyright A. Bolandi al., 2017

Licensee PAGEPress, Italy

Microbiology Research 2017; 8:7289

doi:10.4081/mr.2017.7289

unclear epidemiological aspects of $H$. pylori in fecal samples of dogs, the present investigation was done in order to study the precise status of vacA and $\operatorname{cag} A$ genotypes of H. pylori strains detected in the fecal samples of healthy and complicated household dogs.

\section{Materials and Methods \\ Ethical issues}

All samples were taken from volunteer dogs and written signed consent was obtained from the owners of examined dogs. Sampling procedure was non-invasive and all stages of sampling were done in a way that the lowest levels of pain and damages faced to the examined dogs.

\section{Samples}

From March 2015 to May 2016, overall 150 fecal samples were collected from the household dogs of different sexes (male and female, age 8 months to 12 years) who were referred for routine checks to the clinics of the Small Animal Internal Medicine, Tehran, Iran. Samples were collected randomly from the healthy dogs $(n=90)$ and those that had history of gastric disorders $(n=60)$. The dogs of the treatment group had a history of gastric ulcer, gastritis, chronic 
vomiting and weight loss. Samples were collected in a sterile manner, with care taken to avoid cross-contamination between different sites. Fecal samples were transported to the laboratory at $4^{\circ} \mathrm{C}$. All samples were kept under refrigeration in plastic bags.

\section{DNA extraction and Helicobacter pylori $16 S \mathrm{rRN} A$ gene amplification}

Detection of $H$. pylori strains was done based on the 16S rRNA-based PCR amplification. Genomic DNA was extracted from the fecal samples using a DNA extraction kit for cells and tissues (Fermentas, Germany) according to the manufacturer's instructions and its density was assessed by optic densitometry.

Extracted DNA was amplified for the $16 S$ rRNA gene (F: 5'-CTGGAGAGACTAAGCCCTCC-3' and R: 5'-ATTACTGACGCTGATTGTGC-3') (110 bp). ${ }^{12}$ PCR reactions were performed in a final volume of $50 \mu \mathrm{L}$ containing $5 \mu \mathrm{L} 10 \times$ buffer + $\mathrm{MgCl}_{2}, 2 \mathrm{mM}$ dNTP, 2 unit Taq DNA polymerase, $100 \mathrm{ng}$ genomic DNA as a template, and 25 picomole of each primer. PCR was performed using a thermal cycler (Eppendorf Co., Germany) under the following conditions: an initial denaturation for 2 minutes at $94^{\circ} \mathrm{C} ; 30$ cycles of $95^{\circ} \mathrm{C}$ for $30 \mathrm{~s}, 60^{\circ} \mathrm{C}$ for $30 \mathrm{~s}$, and $72^{\circ} \mathrm{C}$ for $30 \mathrm{~s}$ and a final extension at $72^{\circ} \mathrm{C}$ for $8 \mathrm{~min}$.

\section{Genotyping of $v a c A$ and $\operatorname{cag} A$ genes of Helicobacter pylori}

Presence of the $\operatorname{cag} A$ and the genotypes of vacA (sla, s1b, slc, m1a, m1b and $m 2$ ) alleles were determined using PCR technique. List of primers is shown in Table $1 .{ }^{13}$ The PCR were performed in a total volume of $50 \mu \mathrm{l}$ containing $1 \mu \mathrm{M}$ of each primer, 1 $\mu \mathrm{L}$ of genomic DNA (approximately 200 $\mathrm{ng}$ ), $1 \mathrm{mM}$ of dNTPs mix (invitrogen), 2 $\mathrm{mM}$ of $\mathrm{Mgcl} 2$, and $0.05 \mathrm{U} / \mu \mathrm{L}$ Taq DNA polymerase (invitrogen). PCR amplifications were performed in an automated thermal cycler (Biometra Co., Germany). The following cycle conditions were used for PCR amplification: for vacA: 32 cycles of $45 \mathrm{~s}$ at $95^{\circ} \mathrm{C}, 50 \mathrm{~s}$ at $64^{\circ} \mathrm{C}$, and $70 \mathrm{~s}$ at $72^{\circ} \mathrm{C}$; for $\operatorname{cag} A$ : $1 \mathrm{~min}$ at $94^{\circ} \mathrm{C}, 1 \mathrm{~min}$ at $56^{\circ} \mathrm{C}$, and $1 \mathrm{~min}$ at $72^{\circ} \mathrm{C}$. All runs included one negative DNA control consisting of PCR grade water and two or more positive controls (26695, J99, SS1, Tx30, 88-23 and 84-183).

\section{Gel electrophoresis}

The PCR amplification products (10 $\mu \mathrm{L})$ were subjected to electrophoresis in a $1.5 \%$ agarose gel in $1 \mathrm{X}$ TBE buffer at $80 \mathrm{~V}$ for $30 \mathrm{~min}$, stained with ethidium bromide, and images were obtained in a UVIdoc gel documentation systems (UK). The PCR products were identified by $100 \mathrm{bp}$ DNA size marker (Fermentas, Germany).

\section{Statistical analysis}

Data were transferred to Microsoft Excel spreadsheet (Microsoft Corp., Redmond, WA, USA) for analysis. Using SPSS 16.0 statistical software (SPSS Inc., Chicago, IL, USA), Chi-square test and Fisher's exact test analysis was performed and differences were considered significant at values of $\mathrm{P}<0.05$. Distribution of $H$. pylori genotypes detected in fecal samples of dogs were statistically analyzed.

\section{Results}

Table 2 represents the prevalence of $H$. pylori in of fecal samples of healthy and complicated dogs. Results showed that 13 out of 150 fecal samples $(8.66 \%)$ were positive for $H$. pylori strains. All of the $H$. pylori strains harbored the $16 S \mathrm{rRNA}$ gene. Figure 1 represents the results of the gel

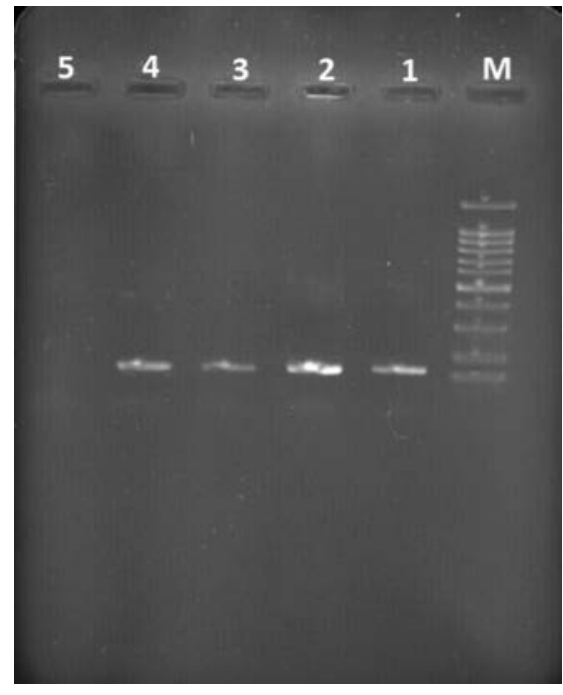

Figure 1. Results of the gel electrophoresis for the $16 S r R N A$ gene of the $H$. pylori strains detected in fecal samples of healthy and complicated dogs. M: 100 bp ladder, 1: Positive control, 2-4: Positive sample for the 16SrRNA gene $(110 \mathrm{bp})$, and 5: Negative control.

Table 1. List of primers used for genotyping of Helicobacter pylori strains detected in fecal samples of dogs.

\begin{tabular}{|c|c|c|}
\hline Genes name & Primer Sequence $\left(5^{\prime}-3^{\prime}\right)$ & Size of product (bp) \\
\hline $\operatorname{VacA} s_{1} a$ & $\begin{array}{l}\text { F: CTCTCGCTTTAGTAGGAGC } \\
\text { R: CTGCTTGAATGCGCCAAAC }\end{array}$ & 213 \\
\hline $\operatorname{Vac} A s_{l} b$ & $\begin{array}{l}\text { F: AGCGCCATACCGCAAGAG } \\
\text { CTGCTTGAATGCGCCAAAC }\end{array}$ & 187 \\
\hline $\operatorname{VacA} s_{l} c$ & $\begin{array}{l}\text { F: CTCTCGCTTTAGTGGGGYT } \\
\text { R: CTGCTTGAATGCGCCAAAC }\end{array}$ & 213 \\
\hline $\operatorname{VacA~}_{2}$ & $\begin{array}{l}\text { F: GCTAACACGCCAAATGATCC } \\
\text { R: CTGCTTGAATGCGCCAAAC }\end{array}$ & 199 \\
\hline VacA mla & $\begin{array}{l}\text { F: GGTCAAAATGCGGTCATGG } \\
\text { R: CCATTGGTACCTGTAGAAAC }\end{array}$ & 290 \\
\hline VacA mlb & $\begin{array}{l}\text { F: GGCCCCAATGCAGTCATGGA } \\
\text { R: GCTGTTAGTGCCTAAAGAAGCAT }\end{array}$ & 291 \\
\hline $\operatorname{VacA~} m_{2}$ & $\begin{array}{l}\text { F: GGAGCCCCAGGAAACATTG } \\
\text { R: CATAACTAGCGCCTTGCA }\end{array}$ & 352 \\
\hline $\operatorname{Cag} A$ & $\begin{array}{l}\text { F: GATAACAGCCAAGCTTTTGAGG } \\
\text { R: CTGCAAAAGATTGTTTGGCAGA }\end{array}$ & 300 \\
\hline
\end{tabular}

Table 2. Prevalence of Helicobacter pylori in different types of fecal samples taken from dogs.

\begin{tabular}{|c|c|c|}
\hline Types of fecal samples & No. samples collected & $\begin{array}{l}\text { Prevalence of } H \text {. pylori by } 16 S \\
\text { rRNA gene amplification (\%) }\end{array}$ \\
\hline \multicolumn{3}{|l|}{ Healthy dogs } \\
\hline Male & 40 & $3(7.50)$ \\
\hline Female & 50 & $2(4)$ \\
\hline Total & 90 & $5(5.55)$ \\
\hline \multicolumn{3}{|l|}{ Complicated dogs } \\
\hline Male & 25 & $5(20)$ \\
\hline Female & 35 & $3(8.57)$ \\
\hline Total & 60 & $8(13.33)$ \\
\hline Total & 150 & $13(8.66)$ \\
\hline
\end{tabular}


Table 3. Distribution of $v a c A$ and cagA genotypes among the Helicobacter pylori strains etected in fecal samples of dogs.

\begin{tabular}{lcccccccc} 
Types of samples & \multicolumn{9}{c}{ Distribution of various genotypes (\%) } \\
(N. positive) & VacA sla & VacA s1b & VacA slc & VacA s2 & VacA mla & VacA m1b & VacA m2 & CageA \\
Healthy dogs (5) & $2(40)$ & $1(20)$ & - & $1(20)$ & $1(20)$ & - & $1(20)$ & $1(20)$ \\
Complicated dogs (8) & $6(75)$ & $2(25)$ & $1(12.50)$ & $3(37.50)$ & $4(50)$ & $1(12.50)$ & $3(37.50)$ & $4(50)$ \\
\hline Total (13) & $8(61.53)$ & $3(23.07)$ & $1(7.69)$ & $4(30.76)$ & $5(38.46)$ & $1(7.69)$ & $4(30.76)$ & $5(38.46)$ \\
\hline
\end{tabular}

electrophoresis for amplification of the $16 \mathrm{~S}$ rRNA gene of $H$. pylori strains. Prevalence of $H$. pylori in healthy and complicated dogs were $5.55 \%$ and $8.57 \%$, respectively. Statistically significant differences were seen for the prevalence of $\mathrm{H}$. pylori between healthy and complicated $\operatorname{dogs}(\mathrm{P}=0.024)$ and also between male and female dogs $(\mathrm{P}=0.038)$.

Table 3 represents the distribution of $v a c A$ and $\operatorname{cag} A$ genotypes among the $H$. pylori strains detected in fecal samples of dogs. VacAs1A (61.53\%), cagA (38.46\%), vacAmla $(38.46 \%)$, vacAs $2(30.76 \%)$ and vacAm 2 (30.76\%) were the most commonly detected genotypes among the $H$. pylori strains of dogs. H. pylori strains of complicated dogs had the higher prevalence and also more diverse studied genotypes. Statistically significant difference was seen for the prevalence of $H$. pylori genotypes between healthy and complicated dogs $(\mathrm{P}=0.035)$.

Table 4 represents the distribution of combined genotypes in the $H$. pylori strains of fecal samples of dogs. We found hat slaCagA (30.76\%), slamla (23.07\%), s2mla (23.07\%) and s2CagA (23.07\%) were the most commonly detected combined genotypes in the $H$, pylori strains detected in fecal samples of dogs. Prevalence of $\operatorname{cag} A$ positive and $\operatorname{cag} A$ negative strains were $46.15 \%$ and $53.84 \%$, respectively.

\section{Discussion}

Humans are recognized as the major host of H. pylori; though, the histopathological inspection represents high prevalence and occurrence of $H$. pylori infections in the gastric mucosa of other mammalian which shows their high capacity as latent hosts for H. pylori strains. ${ }^{14}$

The current research exposed that the dogs and particularly those who had gastric complications like history of gastric ulcer, gastritis, chronic vomiting and weight loss may be the reservoir or original host of the H. pylori. Prevalence of $H$. pylori in fecal samples of dogs was $8.66 \%$ which was considerable high. Low levels of hygiene used for maintenance of dogs, their close contact with stray animals and especially dogs and transmission of pathogenic H. pylori strains from infected owners to dogs are the main factors caused high prevalence of $H$. pylori in fecal samples of our study. However, the prevalence rate of $H$. pylori could be more than the reported prevalence and it is due the fact that the fecal samples of our study were taken from the dogs who were kept in the houses. In the other hand, all of the dogs of our study had owners and kept in hygienic conditions. In addition, household dogs of our study were fed with cooked foods which were free from $H$. pylori strains. This matters will explain the low prevalence rate of H. pylori in fecal samples of dogs in this study. High prevalence of $H$. pylori in raw foods have been reported previously. ${ }^{15}, 16$ Similar findings have been reported previously from Thailand, ${ }^{17}$ Iran, ${ }^{6}$ Denmark, ${ }^{18}$ Egypt, ${ }^{5}$ Italy ${ }^{4}$ and Belgium. ${ }^{19}$

Prevalence rate of $H$. pylori in fecal samples of our investigation $(8.66 \%)$ was lower that of Thailand $(17.30 \%) .{ }^{20}$ Recent researches reported the high prevalence of Helicobacter-like microorganism in clinical samples taken from canine. They showed that Helicobacter-like organisms are extremely prevalent in dogs, with $100 \%$ of random-source dogs, ${ }^{21} 67-100 \%$ of clinically healthy $\operatorname{dogs} s^{21-25}$ and $100 \%$ of laboratory beagles and shelter dogs infected. ${ }^{25,26}$ Helicobacter spp. have also been established in gastric biopsies of $61-95 \%$ of dogs. ${ }^{26,27}$ Torkan and Sakhaei Shahreza $(2016)^{28}$ revealed that 13 out of 240 (5.41\%) gastric biopsy samples of Iranian dogs were positive for $H$. pylori with a higher prevalence of the bacterium in dogs with gastric ulcer $(6.36 \%)$. As far as we know, the present study is the first prevalence report of the detection of $H$. pylori in the fecal samples of dogs.

High prevalence of $H$. pylori strains was accompanied with high prevalence of putative genotypes. As it showed, the most commonly detected genotypes were vacAsla, cagA, vacAmla, vacAs 2 and $v a c A m 2$. The only study which was done in this area, ${ }^{28}$ reported that the prevalence of $v a c A s 1, s 1 b, s 1 c, s 2, m 1 a, m 1 b, m 2$ and $\operatorname{cag} A$ genotypes amongst the H. pylori isolates of gastric biopsy samples of Iranian
Table 4. Distribution of combined genotypes amongst the $H$. pylori strains of fecal samples of dogs.

\begin{tabular}{|c|c|}
\hline Genotypes & Prevalence $(\%)$ * \\
\hline Slamla & 3 (23.07) \\
\hline SIAmIb & - \\
\hline Slam2 & $2(15.38)$ \\
\hline SlaCagA & $4(30.76)$ \\
\hline Slbmla & $1(7.69)$ \\
\hline S1bmlb & - \\
\hline Slbm2 & $1(7.69)$ \\
\hline S1bCagA & $1(7.69)$ \\
\hline Slcmla & - \\
\hline Slcmlb & - \\
\hline S1cm2 & - \\
\hline SlcCagA & - \\
\hline S2mla & 3 (23.07) \\
\hline$S 2 m 1 b$ & - \\
\hline S2m2 & $2(15.38)$ \\
\hline S2CagA & 3 (23.07) \\
\hline CagA+ & $5(46.15)$ \\
\hline CagA- & $8(53.84)$ \\
\hline
\end{tabular}

*From a total of 13 positive strains of $H$. pylori.

dogs were $53.84 \%, 23.07 \%, 0 \%, 23.07 \%$, $30.76 \%, 10.81 \%, 38.46 \%$ and $46.15 \%$, respectively which was similar to our results. Torkan and Sakhaei Shahreza $(2016)^{28}$ in their study revealed that the prevalence of mlasla, mlas $1 b$, m1bslb, $m 2 s 1 a, m 2 s 1 b, m 2 s 2, m 1 a s 2, \mathrm{~m} 1 \mathrm{am} 2$, $\operatorname{cag} A+$ and $\operatorname{cgaA}$ - alleles were $23.07 \%$, $15.38 \%, 7.69 \%, 30.76 \%, 15.38 \%, 15.38 \%$, $7.69 \%, 30.76 \%, 46.15 \%$ and $53.84 \%$, respectively which was relatively similar to our percent. High prevalence of the slam 1a, s1am2, s2m2 and s2m1a genotypes of $H$. pylori have been reported previously in the clinical samples of human beings. ${ }^{29-31}$ In addition, $\operatorname{cag} A$ positive strains have been considered to have a higher pathogenicity for gastric epithelial cells than cagA negative strains of $H$. pylori. ${ }^{32}$ Documented data revealed that $v a c A$ and $c a g A$ genotypes are responsible for adhesion, colonization and invasion of $H$. pylori cells to the gastric mucosa. Therefore, their detection and also study their mosaic structure are useful to 
found new epidemiological aspects of this bacterium in various clinical samples.

\section{Conclusions}

In conclusion, we identified a relatively low prevalence of $H$. pylori in the fecal samples of healthy and complicated dogs in Iran as well as high presence of vacA and $\operatorname{cag} A$ genotypes especially in complicated dogs. Our results indicated that Iranian healthy and complicated household dogs harbor H. pylori in their fecal samples similar in genotype of the vacA and cagA alleles which suggest that complicated and even healthy dogs may be the latent host of the H. pylori and its genotypes. This matter is an important public health threat regarding the close contact of human with household dogs. However, additional studies are required to found the exact role of dogs as a definitive host of the $H$. pylori.

\section{References}

1. Day MJ, Breitschwerdt E, Cleaveland $\mathrm{S}$, et al. Surveillance of zoonotic infectious disease transmitted by small companion animals. Emerg Infect Dis $2012 ; 18$

2. Ghorbani F, Gheisari E, Dehkordi FS. Genotyping of vacA alleles of Helicobacter pylori strains recovered from some Iranian food items. Trop $\mathrm{J}$ Pharm Res 2016;15:1631-6.

3. Atapoor S, Dehkordi FS, Rahimi E. Detection of Helicobacter pylori in various types of vegetables and salads. Jundishapur J Microbiol 2014;7: e10013.

4. Recordati C, Gualdi V, Tosi S, et al. Detection of Helicobacter spp. DNA in the oral cavity of dogs. Vet Microbiol 2007;119:346-51

5. Abdel-Raouf M, Abdel-Gleel Y, Enab A. Study on the role of pet animals for Helicobacter pylori transmission. J Am Sci 2014;10:20-8.

6. Soghra Abdi F, Jamshidi S, Moosakhani F, et al. Detection of Helicobacter spp. DNA in the colonic biopsies of stray dogs: molecular and histopathological investigations. Diagn Pathol 2014;9:50.

7. Wiinberg B, Spohr A, Dietz HH, et al. Quantitative analysis of inflammatory and immune responses in dogs with gastritis and their relationship to Helicobacter spp. infection. J Vet Intern Med 2005;19:4-14

8. Mousavi S, Safarpoor Dehkordi F, Rahimi E. Virulence factors and antibi- otic resistance of Helicobacter pylori isolated from raw milk and unpasteurized dairy products in Iran. J Venom Anim Toxins Incl Trop Dis 2014;20:51.

9. Sicinschi LA, Correa P, Bravo LE, et al. Non-invasive genotyping of Helicobacter pylori cagA, vacA, and hopQ from asymptomatic children. Helicobacter 2012;17:96-106.

10. Alikhani MY, Arebestani MR, Khorasani MS, et al. Evaluation of Helicobacter Pylori vacA and cagA genotypes and correlation with clinical outcome in patients with dyspepsia in Hamadan Province, Iran. Iran Red Crescent Med J 2014;16:e19173.

11. López-Vidal Y, Ponce-de-León S, Castillo-Rojas G, et al. High diversity of vacA and cagA Helicobacter pylori genotypes in patients with and without gastric cancer. Plos One 2008;3:e3849.

12. Ho SA, Hoyle JA, Lewis FA. Direct polymerase chain reaction test for detection of Helicobacter pylori in humans and animals. J Clin Microbiol 1991;29:2543-9.

13. Yahaghi E, Khamesipour F, Mashayekhi F, et al. Helicobacter pylori in vegetables and salads: genotyping and antimicrobial resistance properties. Biomed Res Int 2014;2014:757941.

14. Solnick JV, Schauer DB. Emergence of diverse Helicobacter species in the pathogenesis of gastric and enterohepatic diseases. Clin Microbiol Rev 2001;14:59-97.

15. Gilani A, Razavilar V, Rokni N, et al. VacA and cagA genotypes of Helicobacter pylori isolated from raw meat in Isfahan province, Iran. Vet Res Forum 2017;8:75-80.

16. Atapoor S, Dehkordi FS, Rahimi E. Detection of Helicobacter pylori in various types of vegetables and salads. Jundishapur J Microbiol 2014;7:e10013.

17. Pirarat N, Makbunsri T, Sukkamon S, et al. The relationship between pathological gastric changes and Helicobacter spp. in dog. Thai J Vet Med 2003;33:7380.

18. Wiinberg B, Spohr A, Dietz HH, et al. Quantitative analysis of inflammatory and immune responses in dogs with gastritis and their relationship to Helicobacter spp. infection. J Vet Intern Med 2005;19:4-14.

19. Van den Bulck K, Decostere A, Baele $M$, et al. Identification of nonHelicobacter pylori spiral organisms in gastric samples from humans, dogs, and cats. J Clin Microbiol 2005;43:2256-60.

20. Prachasilpchai1 W, Nuanualsuwan S, Chatsuwan $\mathrm{T}$, et al. Diagnosis of
Helicobacter spp. infection in canine stomach. J Vet Sci 2007;8:139-45.

21. Strauss-Ayali D, Simpson KW, Schein $\mathrm{AH}$, et al. Serologic discrimination of dogs infected with gastric Helicobacter spp. and uninfected dogs. J Clin Microbiol 1999;37:1280-7.

22. Neiger R, Tschudi M, Burnens AP, et al. Diagnosis and identification of gastric Helicobacter species by PCR in dogs. Microb Ecol Health Dis 1999;11:234-40.

23. Jalava K, On SL, Vandamme PA, et al. Isolation and identification of Helicobacter spp. from canine and feline gastric mucosa. Appl Environ Microbiol 1998;64:3998-4006.

24. Happonen I, Linden J, Saari S, et al. Detection and effects of helicobacters in healthy dogs and dogs with signs of gastritis. J Am Vet Med Assoc 1998;213:1767-74.

25. Eaton KA, Dewhirst FE, Paster BJ, et al. Prevalence and varieties of Helicobacter species in dogs from random sources and pet dogs: Animal and public health implications. J Clin Microbiol 1996;34:3165-70.

26. Strauss-Ayali D, Simpson KW, Schein $\mathrm{AH}$, et al. Serologic discrimination of dogs infected with gastric Helicobacter spp. and uninfected dogs. J Clin Microbiol 1999;37:1280-7.

27. Happonen I, Linden J, Saari S, et al. Detection and effects of helicobacters in healthy dogs and dogs with signs of gastritis. J Am Vet Med Assoc 1998;213:1767-74.

28. Torkan S, Skhaei Shahreza MH. VacA, CagA, IceA and OipA Genotype status of Helicobacter pylori isolated from biopsy samples from Iranian dogs. Trop J Pharm Res 2016;15:377-84.

29. Hosseini E, Poursina F, de Wiele TV, et al. Helicobacter pylori in Iran: A systematic review on the association of genotypes and gastroduodenal diseases. J Res Med Sci 2012;17:280-92.

30. Alikhani MY, Arebestani MR, Sayedin Khorasani M, et al. Evaluation of Helicobacter pylori vacA and cagA genotypes and correlation with clinical outcome in patients with dyspepsia in hamadan province, Iran. Iran Red Crescent Med J 2014;16:e19173.

31. Havaei SA, Mohajeri P, Khashei R, et al. Prevalence of Helicobacter pylori vacA different genotypes in Isfahan, Iran. Adv Biomed Res 2014;3:48.

32. Jafari F, Shokrzadeh L, Dabiri H, et al. vacA genotypes of Helicobacter pylori in relation to cagA status and clinical outcomes in Iranian populations. Jpn J Infect Dis 2008,61:290-3. 